\title{
REPERCUSSÃO DE DOENÇAS SISTÊMICAS NO REPARO TECIDUAL
}

\author{
Mariana Achy de Afonseca Acadêmica do curso de \\ Odontologia da Escola Bahiana de \\ Medicina e Saúde Pública \\ Renata Reis de Almeida \\ Acadêmica do curso de \\ Odontologia da Escola Bahiana de \\ Medicina e Saúde Pública
Sílvia Regina de Almeida Doutora em Patologia Humana -
Reis Universidade Livre de Berlim.
Professora Adjunto do curso de
Odontologia da Escola Bahiana de
Medicina e Saúde Pública \\ Alena Ribeiro Alves Peixoto Doutora em Patologia Humana - \\ Medrado Universidade Federal da Bahia. \\ Professora Adjunto do curso de \\ Odontologia da Escola Bahiana de \\ Medicina e Saúde Pública
}

\begin{abstract}
Resumo
Vários são os estímulos, endógenos e exógenos, que podem causar uma lesão tecidual. Neste trabalho são relatadas algumas patologias, a exemplo dos distúrbios circulatórios, desnutrição e doenças associadas ao déficit de cicatrização que podem modular as diferentes fases do reparo tecidual. É de grande relevância o conhecimento das complicações causadas por estas entidades clínicas para o cirurgião-dentista, haja vista que este lida diretamente como o processo de cicatrização através de procedimentos comuns em sua prática clinica.
\end{abstract}

Palavras-chave: Cicatrização; Inflamação; Fatores sistêmicos.

\section{REPERCUSSION FF SYSTEMCI DISEASE IN TISSUE REPAIR}

\begin{abstract}
Several stimuli, endogenous and exogenous factors that can cause tissue damage. This paper reports some pathologies, such as circulatory disorders, malnutrition and diseases related to lack of healing that can modulate the different stages of tissue repair. It is of great importance the knowledge of the complications caused by these clinical entities to the dentist, given that it deals directly to the healing process through common procedures in their clinical practice.
\end{abstract}

Keywords: Healing, Inflammation, Systemic factors 


\section{INTRODUÇÃO}

\section{Aspectos gerais relacionados ao reparo tecidual}

O organismo frente uma lesão desenvolve uma série de mecanismos para reparar e combater o dano causado, caracterizando assim a fase inflamatória aguda. Logo após a lesão ocorre uma vasoconstricção transitória das arteríolas devido à influência nervosa, evitando assim uma hemorragia para o tecido. Este processo é seguido por vasodilatação e aumento da permeabilidade vascular. Há aumento do fluxo sanguíneo que é responsável pelo calor e eritema na região lesada, caracterizando os primeiros sinais da inflamação. Ocorre a formação de um coágulo rico em plaquetas que contém fibrina na área danificada e aglomerado de células sanguíneas, inicialmente polimorfonucleares, como ilusta a Figura 1..$^{(1,5,16)}$

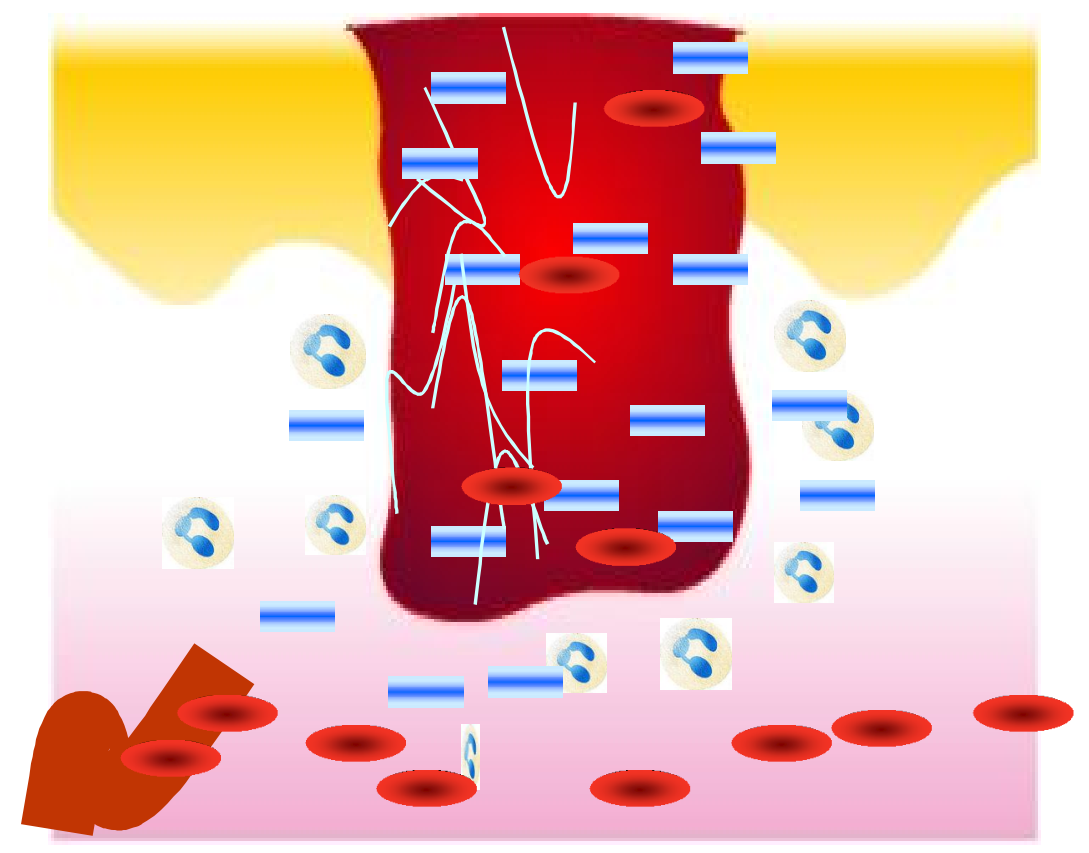

Figura 1 - Formação da rede de fibrina, organização do coágulo e migração de células inflamatórias

A circulação, nesta fase, se torna lenta. Ocorre extravasamento de líquido rico em proteína para o tecido e acúmulo de hemácias nos capilares, aumentando a viscosidade sanguínea. A esse distúrbio dá-se o nome de estase. ${ }^{(27)}$

A estase viabiliza a marginação leucocitária ao longo do endotélio vascular com orientação periférica de leucócitos, principalmente neutrófilos. Os leucócitos se aderem primariamente ao endotélio de maneira transitória (rolagem), depois mais ativamente e, após 
pouco tempo, migram através da parede vascular para o tecido intersticial sob a influência de agentes quimiotáticos. ${ }^{(1,27)}$

Para ocorrer inflamação e reparo é necessária a ação de mediadores químicos advindos do plasma sanguíneo ou das células, sendo que a maior parte dos mediadores tem o potencial de causar efeitos nocivos ao tecido do hospedeiro. ${ }^{(5)}$

O estado de inflamação prolongada, estado agudo inicial estendido por semanas ou meses, se estabelece frequentemente de forma insidiosa como uma reação pouco intensa, geralmente assintomática. É característica de algumas doenças humanas comuns como artrite reumatóide, arterosclerose, diabetes, entre outros. ${ }^{(5,27)}$

O reparo tecidual pode ocorrer de duas maneiras: cicatrização por primeira e por segunda intenção. A cicatrização por primeira intenção é caracterizada por uma ferida com bordas opostas próximas, tempo cicatricial rápido, produção mínima de tecido de granulação e formação de cicatrizes menores. O exemplo mais característico é de um corte em pele com extremidades aproximadas por sutura. A cicatrização por segunda intenção se diferencia pelo fato das bordas da ferida estarem totalmente separadas, apresentando inflamação intensa, resultando em cicatrizes mais extensas. Percebe-se uma perda maior de tecido. Apenas a regeneração das células parenquimatosas não é capaz de recompor a arquitetura original do tecido e ocorre formação abundante de tecido de granulação, caracterizado por intensa proliferação angio e fibroblástica, conforme Figura $2 .^{(1,20)}$

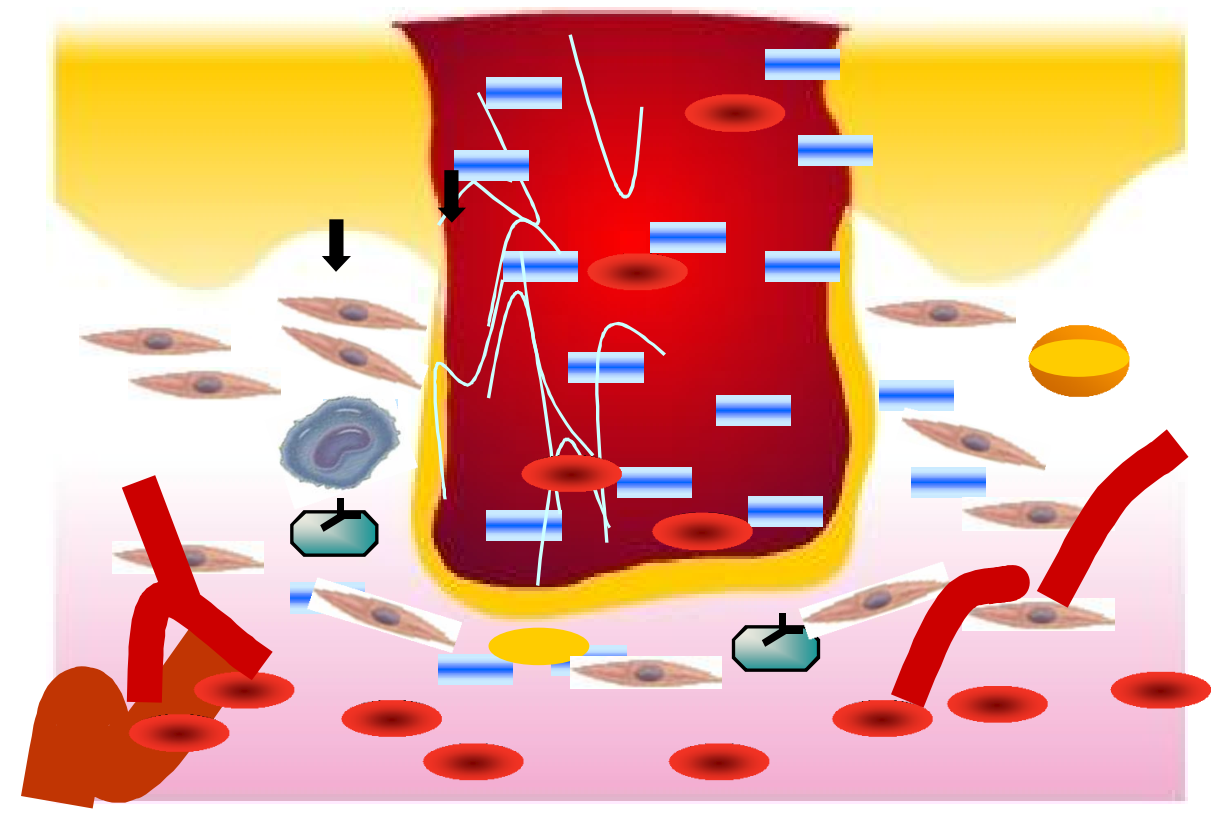

Figura 2 - Desenho esquemático representativo do tecido de granulação, no qual se percebe proliferação fibroblástica e neoangiogênese (setas) 
A reação inflamatória se torna mais extensa pelo fato de que há mais tecido necrótico, maior formação de fibrina e exsudato para se remover. O fenômeno de contração da ferida é o fator principal de diferenciação dos dois tipos de cicatrização. Esta ocorre devido à diferenciação de pericitos e fibroblastos em miofibroblastos. Tais células possuem propriedades e características das células musculares lisas, exibindo o fenótipo contrátil através da expressão de actina alfa de músculo liso (Figura 3) e exercem a função de aproximação das bordas da ferida. ${ }^{(20,27)}$

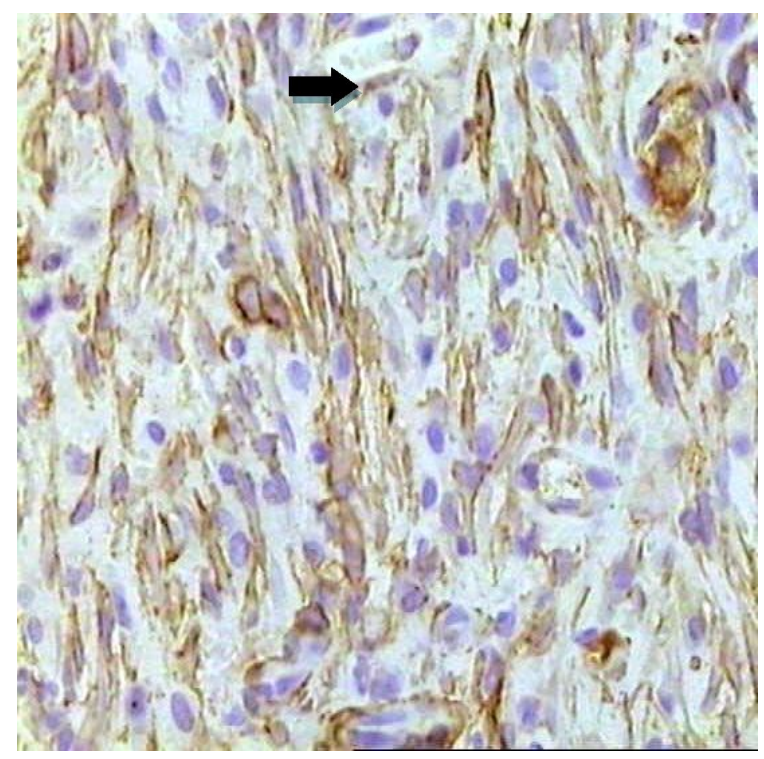

Figura 3 - Coloração imunohistoquímica com o anticorpo anti-alfa actina de músculo liso evidenciando a presença de miofibroblastos (setas) no tecido de granulação. 400x.

A cura total de uma ferida se caracteriza pela maturação da matriz extracelular e durante essa fase é que a cicatriz alcança sua maior força tênsil. Há uma grande e acelerada deposição de colágeno no local. Os mediadores químicos são de grande importância, pois tem forte influência sobre os fibroblastos e estimulam a produção de colágeno, como demonstrado nas Figuras 4 e 5 . $^{\text {(23) }}$ 


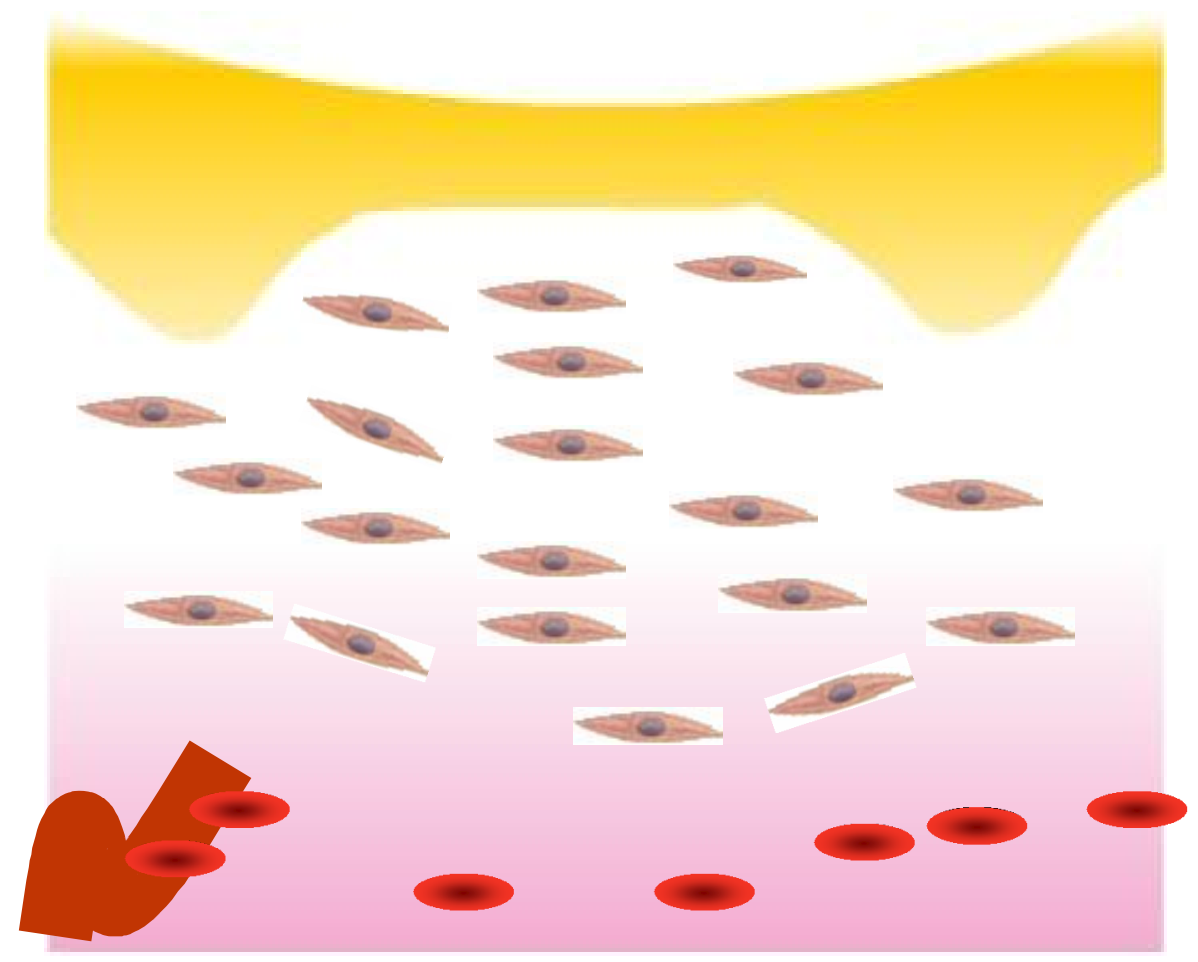

Figura 4 - Desenho esquemático que ilustra a área de fibroplasia

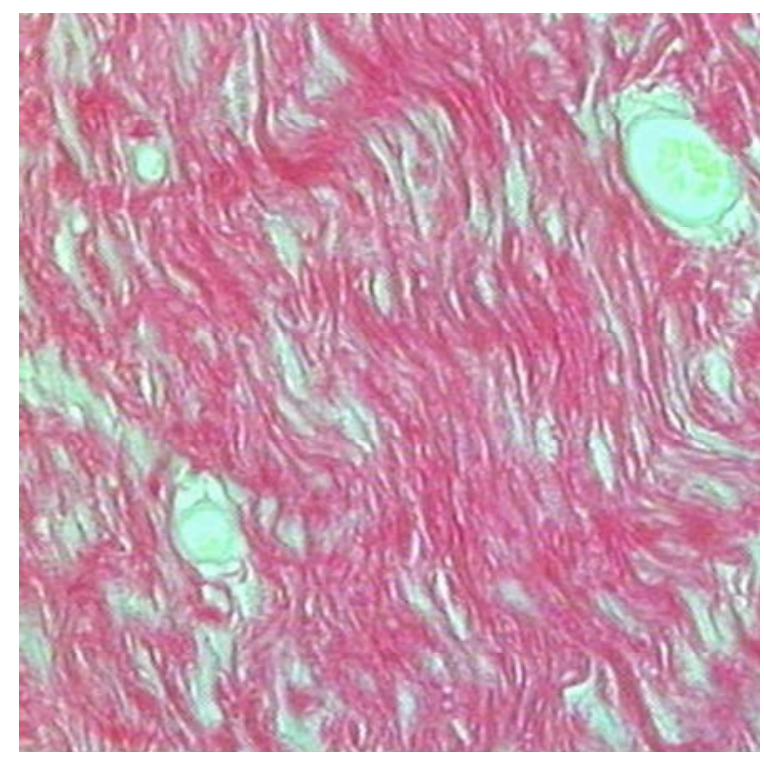

Figura 5 - Deposição de colágeno no interstício, corado em vermelho pelo corante Sírius vermelho. 400x.

O objetivo desta revisão é descrever condições sistêmicas que interferem no reparo tecidual, visando ampliar o conhecimento de possíveis riscos e danos decorrentes da perda da sua homeostase. 


\section{FATORES SISTÊMICOS MODULADORES DO REPARO TECIDUAL}

O reparo necessita de uma série de eventos sequenciais para se consolidar, um conjunto de ações que irão proporcionar ao tecido lesado um remodelamento completo e eficaz. Alterações neste sistema poderão desencadear uma resposta cicatricial anormal ou inferior a esperada. Vários são os fatores fisiológicos e patológicos que irão determinar as possíveis modificações do reparo. Estes incluem desde o atraso cicatricial até o estabelecimento de uma lesão crônica, que não cicatriza.

\section{DISTÚRBIOS CIRCULATÓRIOS}

\section{Diabetes Mellitus}

A resposta inflamatória que sucede a lesão é importante para a rápida cicatrização da ferida. No diabetes, há inicialmente retardo no influxo de células inflamatórias para o local do ferimento, mas, quando estas células se estabelecem, ocorre então o estado de inflamação crônica, dificultando a deposição de componentes da matriz, o remodelamento e, finalmente, o fechamento da ferida. ${ }^{(2)}$

A resposta inflamatória sustentada é acompanhada pela interação de uma classe de moléculas heterogêneas chamadas de produtos finais da glicação avançada (AGEs), importantes mediadores patogênicos das complicações do diabetes, e o seu receptor chamado de RAGE, produzido nos tecidos e vasculatura sob condições fisiológicas. Esta ligação AGEs-RAGE, estimula a liberação de moléculas pró-inflamatórias, como o TNF- $\alpha$ e as metaloproteinases (MMPs) destruidoras da matriz, as quais limitam o fechamento da ferida. Além disso, pode ocorrer a redução da síntese de colágeno por parte dos fibroblastos, comprometendo ainda mais o processo normal de cicatrização. ${ }^{(2,6,15,17,30)}$

A microangiopatia diabética é o termo geral utilizado para denominar as modificações funcionais dos leitos microvasculares, nos quais o endotélio e as células associadas são progressivamente danificados pela hiperglicemia, resultando em oclusão capilar e isquemia, o que pode contribuir para a remoção total do tecido e/ou membro envolvido, e falência de órgãos. ${ }^{(17,30)}$

Várias funções celulares desreguladas estão envolvidas em feridas diabéticas, tais como a resposta deficiente das células $\mathrm{T}$, defeitos de quimiotaxia de leucócitos, fagocitose e 
capacidade bactericida, e disfunções de fibroblastos e células epidérmicas. Estes defeitos são responsáveis pela incapacidade de depuração bacteriana e retardo ou prejuízo no reparo em indivíduos com diabetes. ${ }^{(18,26,29)}$

\section{Hipóxia}

A hipóxia tecidual é um fator sistêmico que interfere na cicatrização e que se constitui na privação dos nutrientes e do oxigênio necessários para as células, que são levados através do sistema microcirculatório, podendo ser derivada da perfusão e angiogênese insuficientes. A hipóxia diminui a deposição de colágeno, inibe a atividade fagocitária e pode levar a multiplicação de microorganismos pela diminuição da atividade leucocitária. ${ }^{(9)}$

A situação de hipóxia prolongada é prejudicial para a cicatrização de feridas. Este fator pode amplificar o início da resposta inflamatória e desta forma, prolongar a lesão e aumentar os níveis de radicais livres de oxigênio Algumas doenças tem a hipóxia como um fator determinante capaz de interferir no reparo tecidual, a exemplo da diabetes. ${ }^{(6,17,30)}$

\section{Hipertensão}

A pressão arterial elevada impulsiona o fluxo sanguíneo em demanda metabólica excessiva, podendo provocar disfunção, danos aos vasos sanguíneos e aos órgãos. A incidência de doenças microvasculares irá determinar significativa diminuição no transporte de sangue para o local da lesão. Visto que a atividade inflamatória e a síntese tecidual são oxigênio-dependentes, pacientes com hipertensão arterial poderiam ter o processo de reparo prejudicado. ${ }^{(6,7)}$ Fawcett et al., ${ }^{(13)}$ estudaram a influência da hipertensão arterial na cicatrização de anastomoses colônicas e observaram que este fator aumenta a incidência de deiscência das anastomoses.

Quanto à síntese de colágeno, os portadores de hipertensão arterial apresentam baixa densidade tanto do colágeno I, quanto do colágeno III durante o período de reparo. ${ }^{(7,16)}$

\section{Isquemia}

Isquemia é definida como sendo o fluxo arterial insuficiente para manter as funções normais teciduais, isto é, a diminuição de nutrientes (glicose, oxigênio, proteínas, vitaminas, 
enzimas etc.) para os tecidos e o retardo na retirada dos metabólitos. Este fato determina a depleção dos níveis intracelulares de trifosfato de adenosina (ATP) e perturba a homeostasia celular. $^{(8,24)}$ Com a evolução da isquemia, a contínua ação desses elementos resulta em alterações celulares progressivas, culminando em necrose. ${ }^{(24)}$

\section{Anemia}

Sabe-se que a hemoglobina é responsável pelo carreamento de oxigênio através dos eritrócitos, para que esse transporte seja eficiente é necessário que os níveis de ferro estejam normais, pois este átomo é responsável pela ligação com o oxigênio. ${ }^{(25)}$

Apesar de muitos nutrientes e co-fatores estarem envolvidos na manutenção da síntese normal de hemoglobina, a deficiência de ferro é a causa mais comum de anemia carencial no mundo. ${ }^{(4,28)}$ A anemia ferropriva, por sua vez, se caracteriza pela diminuição ou ausência das reservas de ferro, que se reflete em mudanças na citomorfologia eritrocitária, causando distúrbio no mecanismo de transporte de oxigênio. ${ }^{(22)}$

O evento comum a todas as anemias é a diminuição dos níveis de oxigênio molecular entregue aos tecidos. No contexto do reparo tecidual, tal fato contribuiria para o retardo do processo em virtude da dificuldade em atender as demandas metabólicas do tecido lesado.

\section{Desnutrição}

O processo cicatricial sofre influência do estado nutricional e de outros fatores. A resposta fibroblástica fica prejudicada pela deficiência de proteína e energia tornando a cicatrização de feridas mais lenta. ${ }^{(10,19)}$ A falta de nutrientes também irá promover diminuição da angiogênese. ${ }^{(19)}$

A vitamina $\mathrm{C}$ é essencial para a hidroxilação da lisina e prolina no processo de síntese de colágeno. É também importante para a produção de elementos de matriz por parte dos fibroblastos e pela integridade capilar. A vitamina $\mathrm{A}$, é essencial à formação e manutenção do tecido epitelial. As vitaminas do complexo B são necessárias para a efetiva ligação cruzada entre as fibras colágenas, para função linfocitária e produção de anticorpos. Os oligoelementos como o zinco, ferro, cobre e manganês, são necessários para a formação do colágeno. A água é o mais importante nutriente que compõe todas as atividades celulares e funções fisiológicas. ${ }^{(10,12,19)}$ 


\section{Alterações Hormonais}

A Dehidroepiandrosterona (DHEA), que é o hormônio precursor dos andrógenos e estrógenos, tem função efetiva sobre o reparo. Ela pode acelerar a cura se convertida para estrogênio ou influir negativamente se convertida para o hormônio andrógeno. Isto pode explicar o fato de homens terem cicatrização mais lenta do que mulheres. É possível que a privação do DHEA ou de seus sucessores possam contribuir para o surgimento de algumas lesões em estado crônico. ${ }^{(14)}$

As contribuições feitas pelo hormônio esteróide no reparo tecidual ocorrem devido a uma regulação de alguns genes responsáveis pela modulação da inflamação, produção de matriz extracelular, diminuição das atividades de proteases, estímulo da angiogênese, contração da ferida e reepitelização. ${ }^{(3)}$

O envelhecimento humano está diretamente ligado ao déficit de alguns desses hormônios o que pode levar a uma complicação na cicatrização de feridas. ${ }^{(3,14)}$

\section{PATOLOGIAS ASSOCIADAS AO DÉFICIT DA CICATRIZAÇÃO}

\section{Escorbuto}

O escorbuto é causado pelo déficit de vitamina C (ácido ascórbico) no organismo, já que esta não é sintetizada pelo corpo humano. O escorbuto é caracterizado clinicamente por alterações no desenvolvimento ósseo em crianças, por hemorragia, e dificuldade de cicatrização de feridas. A deficiência de vitamina C leva a uma resposta imunológica diminuída, aumentando a susceptibilidade à infecção. Além disso, promove a diminuição da proliferação de fibroblastos, angiogênese e aumento da fragilidade capilar. ${ }^{(19,21)}$

A hidroxilação é uma atividade bioquímica importante para a formação de moléculas de colágeno. Existem enzimas importantes na síntese do colágeno, chamadas prolina e lisina hidroxilases. O ácido ascórbico é um agente redutor (antioxidante) muito eficaz, pois ele mantém a prolina e lisina hidroxilase em uma forma ativa, provavelmente por manter seu átomo de ferro no estado ferroso reduzido o que proporciona ao colágeno uma forma helicoidal estável. As moléculas com essa forma deficiente tendem a ter força tênsil diminuída e são mais solúveis e vulneráveis à degradação por enzimas. ${ }^{(19)}$ 


\section{CONSIDERAÇÕES FINAIS}

O reparo tecidual se inicia com o processo inflamatório e tem como objetivo a regeneração das células parenquimatosas do tecido lesado.

A cicatrização de feridas é influenciada por inúmeras variáveis que podem prejudicar ou retardar o reparo. Estas variáveis desencadeiam efeitos sistêmicos de grande relevância que devem ser conhecidos para um melhor controle e manejo de pacientes durante a cicatrização de ferimentos. Em especial, o conhecimento das doenças sistêmicas citadas nesta revisão de literatura, é de grande importância para o cirurgião dentista, haja vista que algumas destas condições apresentam uma alta prevalência na prática clínica. Sendo assim, este profissional de saúde deverá estar preparado para compreender as possíveis intercorrências no processo de reparo tecidual oriundas destes agentes sistêmicos.

\section{REFERÊNCIAS}

1. Agnol MAD. Estudo comparativo entre os efeitos biomodeladores do led e do laser em feridas cutâneas de ratos portadores de diabetes induzido [dissertação]. São José dos Campos (BRA): UVP; 2008.

2. Ahmed N. Advanced glycation endproducts-role in pathology of diabetic complications. Diabetes Res Clin Pract 2005;67(1):3-21.

3. Ashcroft GS, Ashworth JJ. Potential Role of Estrogens in Wound Healing Am J Clin Dermatol 2003; 4 (11): 737-743.

4. Baffa LP, Garcia RLS, Campos AD, Rocha JJR, Feres O. Efeito da anemia aguda na cicatrização de anastomoses colônicas. Estudo experimental em ratos. Rev bras Coloproct, $2005 ; 25(1): 24-30$.

5. Balbino C A, Pereira L M, Curi R. Mecanismos envolvidos na cicatrização: uma revisão. Brazilian Journal of Pharmaceutical Sciences 2005; 41(1).

6. Barbosa JHP, Oliveira SL, Seara LT. O papel dos produtos finais da glicação avançada (AGEs) no desencadeamento das complicações vasculares do diabetes. Arq Bras Endocrinol Metab 2008; 52(6):940-950.

7. Biondo-Simões MLP, Alcantara EM, Dallagnol JC, Yoshizumi KO, Torres LFB, Borsato KS. Cicatrização de feridas: estudo comparativo em ratos hipertensos não tratados e tratados com inibidor da enzima conversora da angiotensina. Rev Col Bras Cir 2006; 33(2): 74-78.

8. Bishop A. Role of oxygen in wound healing. J Wound Care 2008; 17:399-402.

9. Clark JJ. Wound repair and factors influencing healing. Crit Care Nurs Q 2002; 25(1):1-12.

Revista Bahiana de Odontologia, Salvador, dez. 2012; 3(1): 63-75. 
10. Coelho-Lemos ICM. Influência da desnutrição intra-uterina na cicatrização da parede abdominal de ratos lactentes avaliada mediante estudo tensiométrico e da morfometria do colágeno [tese]. Curitiba (BRA): UFP; 2003.

11. Cotran RS, Collins T, Kumar V. Robbins \& Cotran - Patologia estrutural e funcional. In: Cotran RS, Collins T, Kumar V. Reparo dos tecidos: Crescimento celular, fibrose e cicatrização de feridas. $6^{\text {a }}$ ed. Rio de Janeiro: Guanabara Koogan; 2000. p. 79-100.

12. Demling RH. Nutrition, anabolism, and the wound healing process: an overview. Eplasty. 2009; 9: e9.

13. Fawcett A, Shembekar M, Church JS, Vashisht R, Springall RG, Nott DM. Smoking, hipertension, and colonic anastomotic healing; a combined clinical and histopathological study. Gut 1996; 38(5):714-8.

14. Gilliver SC, Ashworth JJ, Ashcroft GS. The hormonal regulation of cutaneous wound healing.Clinics in Dermatology 2007; 25, 56-62.

15. Goldin A, Beckman JA, Schimidt AM, Creager MA. Advanced glycation end products. Sparking the development of diabetic vascular injury. Circulation 2006;114(6):597-605.

16. Kumar V, Fau sto N, Abbas A K. Robbins \& Cotran - Patologia: bases patológicas das doenças. In: Kumar V, Fausto N, Abbas A K. Inflamação aguda e crônica. $7^{\text {a }}$ ed. Rio de Janeiro: Elsevier; 2005. p. 49-89.

17. Lin L. RAGE on the toll road? Cell Mol Immunol 2006; 3(5):351-8.

18. Loots MA, Lamme EN, Zeegelaar J, Mekkes JR, Bos JD, Middelkoop E. Differences in cellular infiltrate and extracellular matrix of chronic diabetic and venous ulcers versus acute wounds. J Invest Dermatol 1998; 111: 850-857.

19. MacKay D, Miller AL. Nutritional Support for Wound Healing . Alternative Medicine Review 2003;8(4).

20. Mandelbaum SH, Di Santis E, Mandelbaum MHS. Cicatrização: conceitos atuais e recursos auxiliares - Parte I. An bras Dermatol, 2003; 78(4):393-410.

21. Manela-Azulay M, Lacerda CAM, Perez MA, Filgueira AL, Cuzzi T. Vitamina C. An bras Dermatol. 2003; 78(3):265-274.

22. Osório MM. Fatores determinantes da anemia em crianças. J Pediatr. 2002; 78(4):269-78.

23. Peppa M, Brem H, Ehrlich P, Zhang J,Cai W, Li Z et al. Adverse effects of dietary glycotoxins on wound healing in genetically diabetic mice. Diabetes 2003; 52.

24. Rodriguez PG, Felix FN, Woodley DT, Shim EK. The role of oxygen in wound healing: a review of the literature. Dermatol Surg 2008; 34:1159-1169.

25. Sen CK. Wound healing essentials: let there be oxygen. Wound Rep Reg 2009; 17: 1-18. 
26. Sibbald RG, Woo KY. The biology of chronic foot ulcers in persons with diabetes. Diabetes Metab Res Rev 2008; 24(Suppl 1):25-30.

27. Silva JC. Avaliação do uso do laser de baixa potência e droga fotossensibilizadora no processo de cicatrização [dissertação]. São José dos Campos (BRA): UVP; 2003.

28. WHO. Technical Report Series, 580. Control of nutritional anaemia with special reference to iron deficiency. Geneva: WHO; 1975.

29. Woo K, Ayello EA, Sibbald RG. The edge effect: current therapeutic options to advance the wound edge. Adv Skin Wound Care 2007; 20:99-117.

30. Yonekura H, Yamamoto Y, Sakurai S, Watanabe T, Yamamoto H. Roles of the receptor for advanced glycation endproducts in diabetes-induced vascular injury. J Pharmacol Sci 2005; 97(3):305-11. 